be shaken physically and frightened morally; he is told to rest; he has nothing to do ; all his kind friends who call on him tell him of the Messrs. So-and-so, all of whom met with "just such an accident," and who became "quite paralysed after a time." His doctor asks him if he feels this and that; his lawyer shakes his head mysteriously, and the last straw that often breaks his back is either the very grave face and sympathetic tone of the "Company's doctor," that convinces him that something is very seriously wrong, or, on the other hand, the extreme cheerfulness of that functionary, which is, to the patient's mind, distinct evidence that his hopefulness is all put on. The man becomes really ill, but the region of illness is idea.

6. The degree to which the form of malady enters into the complicated histories of chronic cases of nervous disease, is one of its most interesting features; because it often happens, on the one hand, that such symptoms as it can produce may be supposed to be the result of real organic lesion, and so place the case among the category of incurable diseases, and, on the other, that a recognition of their true nature may lead to their speedy removal, and an amount of encouragement that shall be very useful in the alleviation of more grave derangement. A few facts of an actual case will illustrate this point. A married lady, the mother of four children, and the victim of several mishaps, suffered much from hæmorrhoids, fissure of the anus, great debility, and convulsive seizures of epileptoid character. She was intensely anæmic, had much headache, attacks of occasional delirium, sometimes hysteric in form, but sometimes passing beyond that type. There was much to distress her in surrounding circumstances, impaired fortune, and a necessity for exertion beyond her powers. She gradually became paraplegic, lost control over the sphincters, and was confined to bed. Her nights alternated between fainting and delirium, the passage from the one to the other being marked by some convulsive seizures, of what may be termed hysterico-epileptic character. This state of affairs continued for many months ; the helplessness of the patient, and the distress of her husband, increasing week by week. Upon examination, I found inability to move the lower limbs to any extent, occasional involuntary micturition, and escape of fæces; but the nutrition of these limbs was not specially affected, there was no alteration of sensibility, no bed-sore, and no tenderness of spine on deep pressure; but there was a great sorrow on account of her helplessness, and an admission that she had for a long time "feared that she might become paralysed." This patient was quite well in a fortnight, and the treatment that was used was that which I have already described. The first night that she was taken to the hospital, the evacuations occurred in bed; but she was told by the nurse that "such things were not allowed," and they never occurred again.

The subsequent history of the case was one of the kind that might be supposed; some of the nervous symptoms remained in a diminished degree, but the general health became fairly good, and the paraplegia disappeared altogether.

7. The diagnosis of the condition which I have endeavoured to describe is to be framed-I. Upon a consideration of the mode of onset of the symptoms, and especially upon the discovery of an idea which should take possession of the mind, and lead to its own fulfilment; 2 . Upon an estimate of the symptoms actually present, and, particularly, upon the discovery of phenomena which can not be explained by what we know of the history of organic lesion. Here I would draw attention to such anomalies as these :- $a$. That a patient cannot raise the heel off the bed, or draw it upwards towards the body, and yet that he or she can sit up in bed, or lie down voluntarily and slowly without assistance, or can turn from side to side without aid; $b$. That this apparently absolute paralysis co-exists with perfect sensibility of skin, electro-muscular sensibility, and contractility; with unimpaired nutrition of the muscles and the skin; and with no sign of disease in the spinal bones; or, c. That there is absolute inability to maintain the erect position, although there is the possibility of moving the limbs in any direction, and this, without failure of irritability, or nutrition, or sensation. 3. Upon the observation of the effects of treatment; $a$. The absence of beneficial result from ordinary medication; and, $b$. The almost immediate advantage to be seen on the adoption of methods which are directed to the alteration of idea.

8. The treatment is that which I have already described, viz.:$a$. A real, earnest dealing with the case, as one of grave character, although not of the kind supposed; $b$. A confident expression of hope, if certain plans are followed out; and the steady conveyance of this hope habitually to the patient, not only by the physician, but by those in constant contact with the patient. This is, I believe, of paramount importance; and hence it is that much more can be done in hospital than in private practice. Still, sometimes, it is possible to place a patient away from home, with a well-instructed nurse, and so gain the main points of hospital treatment. This it is desirable to do when- ever it is possible; but sometimes much may be gained by sending an accomplished nurse to the house to take the patient well into her own hands, and out of those of kind but over-anxious friends. c. Making the patient attempt to walk at once, and at stated intervals, with support on each side, the amount of support to be gradually diminished day by day. $d$. The employment of faradisation to the muscles, partly as a moral and mental agent, partly as a physical occasion of muscular contraction. It is important to discover the muscles which are the most flaccid and the least susceptible of voluntary work, and to direct especial attention to their treatment. $e$. Friction and passive movements of the limbs. g. Such regiminal, dietetic, and medicinal means as may be required by the special condition of the patient.

By such means as these, and by their careful variation and manipulation, I believe and know that many cases of apparently grave disorder of the nervous centres, may be removed entirely; and that, in other instances, when the ideal affection is grafted upon organic lesion, much may be done to remove the former, and afford so much of the stimulus of hope that the cure of yet graver symptoms is brought within the range, not only of possibility, but of probability, and of actual fact.

\section{ON THE REGISTRATION OF DISEASES.*}

By G. H. PHILIPSON, M.A., M.D.Cantab., M.R.C.P.Lond., Physician to the Newcastle-upon-Tyne Infirmary, etc.

THE study of the diseases which prevail, or are common, forms a portion of our daily occupation. By the interchange of ideas consequent thereon, many important facts and phenomena respecting their natural history and pathology become imparted from one to another, and are thus not only preserved, but, in addition, may be suggestive of new views in other minds. By the mere mention that a contagious and epidemic disease is raging in a district, a warning is given to others in distant parts, who at once have their attention riveted to the probability of their own district becoming similarly affected, make timely preparation for the approach of the enemy, whose course, happily, may be intercepted, and the magnitude of the calamity lessened. This is especially the case with what may be termed the fresh epidemic diseases, or those which are new in a district, as the occurrences of diphtheria and cerebro-spinal meningitis within the last few years. If we were not, in this way, made acquainted with the peculiarities or characteristic symptoms of such diseases, how could they, with any certainty, be recognised by those who had been precluded the opportunity of observing them? Again, the more severe epidemic diseases are frequently preceded by a similar but milder disease, the resemblance being in the similitude of the symptoms, the mild disease giving a timely warning, or occupying the position of herald to the graver disease. These forerunners, then, are to be regarded, and the incidents which are happening to others heeded; for by such means we may, peradventure, prevent, mitigate, or arrest the prevalence of an epidemic outbreak.

If, by any possibility, we mitigate the outbreak of an epidemic disease, we are rendering service to the public by screening them not only from that disease, but from others which have been observed to follow closely in its footsteps, and which are known to be of a much more fatal character. When it is considered how exceedingly rare it is for even a single individual, and certainly for a collection of people, to pass through an outbreak of a contagious or epidemic disease, without being taken possession of thereby, unless they have been rendered impenetrable to the influencing effects by a former attack of the same disease, all our efforts should be roused to the investigation of these important subjects. For how often does it happen in those who have recovered from an attack of one of the epidemic diseases, that the constitution is so weakened that the former state of vigour is never re-attained or, if the health appear re-established, the ground is all prepared for the more ready occupation by some other disease; or, after a varying time, the strength gradually declines, finally yielding, without any organic disease being discoverable.

The study of epidemic diseases, therefore, calls for our best energies, but is yet quite in its infancy. The labourers may be said to have only passed the threshold. This is not from the number of those thus employed having been small, or from the workers having been idle or unable to solve the many difficult problems. A large portion of those who have selected this field for their labour have been from the foremost ranks of men of science, and have shown an affection for their work, which could with difficulty be excelled; even some, by their devotion, have sacrificed their very lives. In a measure the scanty results

* Read in the Public Medicine Section at the Annual Meeting of the British Medical Association in Leeds, July 1869. 
may have been caused by some of the inquirers having only prosecuted their researches during the time when an epidemic was prevalent, and not also when absent. It is absolutely necessary that the inquiry should be continued after the epidemic has passed away. When an epidemic disease unhappily visits a neighbourhood, all the community become excited ; all thoughts are roused; some facts may possibly be observed, and the cause of the visitation conjectured ; but when the mortality again declines, and the health of the locality returns to its former condition, those thoughts which had been occupied with such fearful forebodings become engaged with other subjects, and all the distressing circum. stances are soon forgot, or certainly remembered as of the past. It may be, in some favoured district, that an official inquiry is instituted, and, after a certain time occupied in eliciting evidence and the examination of witnesses, a report is published, which necessarily cannot be very complete, because the most important element for its perfection is wanting; namely, reliable data upon which to base the deductions.

The diseases which prevail, or have most influence upon the community, are those which belong to the contagious and epidemic division, or, according to the new nomenclature of diseases, "general diseases, which appear to involve a morbid condition of the blood." What the exciting cause of these diseases is, whether they are due separately or conjointly to changes in the temperature, moisture, pressure, composition, electric condition, or the amount of ozone in the atmosphere, is not the object of this communication. But, of all these causes, that the changes in the temperature occupy a prominent position will readily be admitted. In great changes or extremes in the temperature, a corresponding increase or decrease of sickness is always noted. In a very hot summer, derangements of the viscera connected with the mucous membrane of the stomach and intestines occur; that extensive and internal tract reciprocates with the surface of the body, under the agency of external heat ; on the contrary, in extreme cold weather, the mucous membrane of the air-passages becomes affected, and the important structures in contiguity suffer.

Season has a great influence upon certain diseases. Of all the seasons, the Registrar-General thinks "that summer is the healthiest, winter the most unhealthy." This is the reverse of what was the case in former times, when the number of deaths occurring in the summer always greatly exceeded those in the winter. At the present time, the winter mortality is by far the greatest, unless an epidemic outbreak have occurred to swell the list of summer deaths. Here is an evidence of the good effect of legislative interference in the establishment of sanitary measures in most of the large towns.

It is now well known that the entire class of infectious and epidemic maladies exhibit variations, not only in intensity but also in fatality, from year to year. These propositions are illustrated by the following calculations, which have been made from the Reports of the Newcastleupon-Tyne Dispensary, for the last ten years. The percentage of cases of a few selected diseases, in comparison with the whole number of medical cases treated at that institution, being as follows :

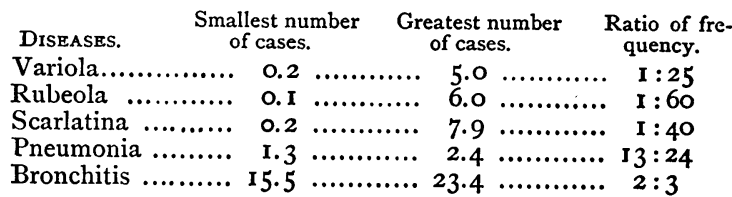

In the diseases-variola, rubeola, and scarlatina-all produced by some alteration in the constitution of the blood, the fluctuations in the number of cases is very considerable; whereas in pneumonia and bronchitis, diseases primarily due to some structural alteration, the variations are very small.

To illustrate, also, the proposition, that the fatality of these diseases is very variable, in comparing one year with another: in the same ten years, the percentage of deaths from variola, taking the whole number of cases in each year, was as low as 6.0, and as high as 23.4, or four times as fatal ; from rubeola, as low as 0.9 , and as high as 17.0, or eight times as fatal; from scarlatina, as low as 2.6, and as high as 20.0, or eight times as fatal.

Again, it may be said by some, that the right way to investigate the violence or strength of an epidemic is to refer to the number of fatal cases during a visitation. Without doubt this mode of procedure will illustrate the fatality of an epidemic, but cannot show its magnitude. In all epidemic outbreaks, the number of recoveries and deaths must be compared with each other, with the number of those affected, and with the aggregate of those who have escaped. In this manner a measure is obtained of the severity of the epidemic, from time to time, in the same outbreak, and in former visitations of the same disease. If the explanation of the causes of epidemic diseases have to be sought by a reference to the number of deaths, this is too long deferred. The mortality of a disease is by no means an accurate measure of its prevalence. It is true that from the right statements of the fatality of an epidemic some lives may be saved, it may be, from the institution of more stringent sanitary measures. We must strive for something more than this. Endeavours must be made to save the earlier of those who are stricken down. This can only be hoped for by having some "mark" or "sign" to guide us; some "caution", or rather "previous notice", which is to be gained by the regular observation and registration of the diseases which are daily prevailing in our midst, in our cities, towns, villages, and rural districts.

Having indicated some of the advantages that are to be gained by studying more closely the diseases which are prevalent, more especially so, by the employment of a methodical system of registration, we would now direct your attention to the manner in which this may be accomplished.

In a system of registration, it is necessary, Ist, to collect facts ; 2nd, to classify and compute the facts that have been collected.

In the collection of the facts, two elements are needful; the assistance and cooperation of the whole available scientific strength, and uniformity in the system of observation, consisting of a simple and easy mode of recording the notes.

A single individual can do little without the help of others in the carrying out of any plan. From his isolated position, the vast extent of the population, the great difference of circumstances in which they are placed, it is clear that a result, and that even greatly deficient in the approximation to perfection, can only be obtained by the united and devoted efforts of a band of workers. For as, in mechanics, power is obtained by a combination of forces all directed to the same object, so, in the investigation of some of the recondite problems in the science of medicine, a leaguing together of those so employed is absolutely necessary. The advantages that would accrue, as well as being of general value, would also redound upon each individual. In the words of the Registrar General, "the register of the medical practitioner would, at the end of a few years, be of incalculable interest to him; he might refer back to it for important information, transmit it to his sons or successors in practice, analyse the results of his experience, and, in conjunction with his brethren all over the country, would ultimately accumulate a large mass of materials which could not fail to advance medical science"; and as "medical science is based upon extended observations," the collected notes of a number of individuals scattered over a district would do far more for the advancement of this science than the writings of single individuals, no matter how highly gifted in power of observation and expression they might be.

In the classification and computation of the facts collected, a properly constituted plan is absolutely necessary, which could best be carried out under the direction of a central authority, independently of the observers of the facts.

At once it will be recognised, that the fundamental step for the statistical registration of diseases must be uniformity in the system of registration. Such has been effected by this great and powerful Association. For, in the year 1865 , at the annual meeting held at Leamington, a Committee was appointed "to encourage the registration of diseases," who agreed upon a form of return for uniform registration, which form was approved in 1867, at the annual meeting held at Chester, and afterwards issued to the members. The form is simple, yet complete, and is one which may be nationally adopted. As stated in the report of the Committee on the observation and registration of disease, presented in 1868, at the annual meeting held at Oxford, "the registration of disease occurring in public practice was commenced upon the same plan, and with the same list of diseases, at the following places; Manchester and Salford, under the direction of the Sanitary Association; St. Marylebone, London, by Dr. Whitmore; Birmingham, by Dr. Alfred Hill; and Newcastle-upon-Tyne and Gateshead, by the Northumberland and Durham Medical Society." Monthly or more extended reports, based upon these returns, with observations in meteorology, have also been issued. It is only just, also, to add that, for some years previous to 1868, the registration of diseases had been carried on at St. Marylebone, London, Manchester and Salford, and Newcastle-upon-Tyne and Gateshead. The plan, however, was different, and was in each case modified, in 1868 , to that recommended by this Association.

The possibility of the registration of diseases having been exemplified; and the manner in which it may be best accomplished having been fully delineated, what is wanting now is, that the system should become general ; in a word, that the statistical registration of diseases should be "national". There exists a national system of registration of the causes of death; so there might be a corresponding national system of registration of the actual cases of disease, which might justly be called "vital statistics," and which would indicate the resistance of one portion of the community: 
against disease as compared with another. Undoubtedly, the statistics of a single town are instructive; far more instruction, however, will be gained from the compared statistics of various and many towns. In addition, also, it would tend to throw light upon the causes of diseases, on the means of their prevention, and the right understanding of their etiology, the greatest reward of the worker in the wide expanse of "the science of medicine."

\section{ON BICHLORIDE OF METHYLENE.}

\section{By BENJAMIN W. RICHARDSON, M.D., F.R.S.}

THB recent notes in the JOURNAL on bichloride of methylene call for one or two explanatory sentences bearing on the action of that substance. I shall say what has to be said best by stating briefly the physical character of the bichloride, and the relation it bears to chloroform and other allied anæsthetics.

Chloroform and bichloride of methylene belong to one family of chemical organic bodies, in which family, carbon, as the base, combines with hydrogen and chlorine in different proportions. If one opens the hand, extends the thumb, and lets the extended thumb represent the carbon, all the other combinations of the group can be shown with the four fingers. Let the thumb represent carbon; extend the first finger, and let it represent hydrogen; keep the second, third, and fourth fingers together, and let them represent chlorine: the hand describes the composition of chloroform, which is composed of $\mathrm{C} . \mathrm{H} . \mathrm{Cl} \mathrm{Cl} \mathrm{Cl}$. Bring up the second finger to the first, and let it now represent hydrogen, and the hand describes the composition of bichloride of methylene, which is composed of $\mathrm{C} . \mathrm{H} \mathrm{H} . \mathrm{ClCl}$. Bring up the third finger to the second and first, and let it also represent hydrogen, and the hand describes chloride of methyl, which is composed of $\mathrm{C} . \mathrm{H} \mathrm{H} \mathrm{H}$. Cl. Bring the fourth finger to the other fingers, and let it, with the others, represent hydrogen, and the hand describes marsh gas, $\mathrm{C}$. $\mathrm{HHHH}$, or, as it is called chemically, hydride of methyl. Or, let the fingers altogether represent chlorine, and the hand describes the tetrachloride of carbon, which is composed of $\mathrm{C}$. $\mathrm{ClClClCl}$, the hydrogen of marsh-gas being entirely substituted by chlorine. In these compounds, we have a com plete chemical anæsthetic family group. Every member of the group produces sleep, and insensibility to pain, when inhaled by the living animal. In this respect, all the members of the family resemble each other in one leading characteristic, but they differ in detail; the difference turning on difference of physical property, and this, again, turning on the proportion of chlorine.

Let us compare, from this point of view, chloroform with bichloride of methylene. Chloroform, we have seen, is composed of $\mathrm{C} . \mathrm{H} . \mathrm{ClClCl}$, and bichloride of methylene is composed of $\mathrm{C} . \mathrm{HH}$. $\mathrm{ClCl}$. Thus, chloroform has one more equivalent of chlorine than bichloride of methylene, and bichloride of methylene has one more equivalent of hydrogen than chloroform-in fact, in it, an equivalent of hydrogen is substituted for an equivalent of chlorine in the chloroform.

This difference causes essential alterations in the physical property. The combining weight of chlorine is as thirty-five to one of hydrogen; the difference causes an alteration in the specific gravity, the vapour density, and the boiling point of the two fluids. For example, the vapour density of chloroform, taking hydrogen as unity, is 59.75 ; of the bichloride of methylene, 42.5 . The boiling point of chloroform is $\mathrm{I}^{2} \mathrm{deg}$. Fahr., and that of bichloride of methylene (according to the researches of Mr. Perkins, who has corrected the earlier observers), IO4 deg. Fahr.

In turn, the difference of physical property modifies action. The lower boiling point of the bichloride causes it, when exposed to the air, to diffuse with greater rapidity than chloroform. I have seen it diffuse so rapidly that the condensed water from the breath of the patient became frozen in the inhaler. For this same reason, there is also a quicker diffusion of the vapour in the lung, and a quicker action on the blood. Again, for the same reason, there is quicker elimination of the substance from the body, with a less! expenditure of the animal force, than occurs with the heavier chloroform.

In other respects, bichloride of methylene resembles in action the remaining chlorides; i.e., it causes, sometimes, muscular excitement, and, occasionally, vomiting. These symptoms are more or less severely produced by all the representatives of the series; the effects varying with the amount of the chlorine. The chloride of methyl produces very little excitement, and no vomiting. Chloroform produces great excitement, and vomiting frequently; the latter symptom being often active and prolonged. Bichloride of methylene holds a place, in these respects, between the two.
When we correctly understand these points of difference between bichloride of methylene and chloroform, we see, with a little more reflection, what difference of symptoms will result from their inhala. tion, and what differences of method are required in their administration. If we diffuse equal portions of chloroform and of bichloride in an equal space of air, at the same temperature, each in a closed chamber, and place two animals of the same kind, weight, and condition, one in each chamber, the animal inhaling the vapour of the bichloride is narcotised more quickly than the animal in chloroform, and with less excitement; being narcotised, it will remain, while in the same atmosphere, as deeply narcotised as the animal in the chloroform, but it will die later; further, if it be taken out when it has ceased to breathe, it will more readily recover under artificial respiration than the animal which has ceased to breathe in the chloroform. If, however, two animals be exposed to the same quantity of the two narcotising agents, at the same temperature, not in a confined chamber, but in an open space, there will be difference of action. The animal breathing the bichloride of methylene, unless the dose be very large, will be excited, and will possibly not pass into the third degree of narcotism at all; while the animal breathing the chloroform will be narcotised to the third degree. The reason of this difference is obvious enough, and is, that the lighter bichloride has been lost by diffusion in the air, more rapidly than the heavier chloroform. Again, if the two animals be narcotised to the same degree, one with the bichloride, the other with chloroform, and the narcotics be withdrawn at the same moment of time, the animal narcotised with the bichloride will recover more quickly than the animal narcotised with chloroform, and the return to the natural temperature, from the reduced temperature to which both will have been brought, will also be more quickly effected.

These facts explain all the anomalies which those who exhibit bichloride of methylene to the human subject have so often observed; they explain, moreover, that the anomalies depend, not on the substance, but on the mode in which the substance is administered. Bichloride of methylene, owing to its rapid diffusion, can be made to produce good anæsthesia for short operations within the minute; an operation lasting two minutes may be performed, and, the vapour being withdrawn, recovery may be perfect in five minutes. We can scarcely want anything more in the direction of rapidity of action. Bichloride of methylene can be made to produce deep anæsthesia in four minutes; and, when a long operation has to be performed, the sleep can be sustained, without a struggle, for an hour (I am speaking from experience); recovery, when the vapour is withdrawn, being complete in from ten to twenty minutes. We can scarcely want anything more in the direction of prolonged action.

To obtain these two different results, there must be a principle in the method of administration of the bichloride. To produce the rapid effect, the agent must be given as Mr. Rendle gives it; $i$. e., its vapour must be confined in a small, simple, hollow cylinder, which adapts itself to the mouth and nostrils at one end, and is perforated with holes, for admission of air, at the other; the cylinder being lined within with loose demette. The diffusion of a drachm of the fluid is sufficient for very short operations when applied in this way. To produce the prolonged effect, the same cylinder may be used, but air must be more freely admitted by holding the inhaler more loosely over the mouth and nostrils; and, when the insensibility is complete, the administration must be continued in full, for a minute or two, unless some urgent symptom should interfere, until the organism is well charged with the narcotic A sufficient charge once introduced, the sleep may be sustained by the simple process of readministration, carrying the effect each time a little longer than the period when the anæsthesia is perfect and the voluntary muscles are quiet.

The question of the age of the patient has been adduced as having a bearing upon the action of bichloride of methylene and of chloroform, the idea being that chloroform is best suited for the young. There is really no ground whatever for the fancy, except this: that, as the respiration of children is quicker than that of adults, they come more quickly under the influence of the vapour of the bichloride, because they inspire more of it. Hence, to babes and young children, the vapour, even for short operations, should be administered more diluted with air than to adults. Happily, if in young children or other young animals quickly narcotised with bichloride of methylene, the respiration be for a moment checked, prompt artificial respiration, gentle but prompt, suffices to restore animation with a certainty that is remarkable. I have restored suspended respiration in a young animal under bichloride of methylene, two and even three times after respiration had ceased.

A practice has been suggested of first putting the patient to sleep with the light bichloride, and of keeping up any required prolonged effect with chloroform. I have already said enough to shew that this practice is unnecessary. I would add, now, that it is excessively dan- 